\title{
Clinical Experiences and Clinical Trials
}

\section{To the Editor:}

March 28, 2008

The title of the November "In Session" with Stephen R. Marder, MD, ("Newer Antipsychotics and the Difference between Clinical Experiences and Clinical Trials" ${ }^{1}{ }^{1}$ implies that the results of clinical trials may be equivalent to or perhaps even more doubtful than clinical experience in evaluating antipsychotics.

The Clinical Antipsychotic Trails of Intervention Effectiveness (CATIE) study, the largest, longest independent study of atypical antipsychotics in chronic schizophrenia, found no health advantage for these medications over an older, far less expensive drug, perphenazine. While patients stayed on olanzapine longer than other medications $^{2}$ there were no significant advantages for any atypical as compared to perphenazaine on measures of symptoms, ${ }^{3}$ neurologic side effects, ${ }^{2}$ neurocognition, ${ }^{4}$ quality of life, ${ }^{5}$ employment, ${ }^{6}$ or violent behavior. ${ }^{7}$ Patients assigned to perphenazine were more likely to change medications due to extrapyramidal symptoms (EPS) but there was no significant difference between perphenazine and any atypical antipsychotic on the broader measure of time to discontinuation for any adverse effect or on standard measures of neurological side effects, and the difference in discontinuation for EPS was small $18 \%$ for perpehanzine vs $4 \%$ for ziprasidone and $2 \%$ for olanzapine).

Marder identifies three limitations of CATIE. First, he suggests that the patients may have been too severely ill or too chronically ill to be informative. However, participants in CATIE were quite similar to those seen in seven other major trials of atypical antipsychotics, ${ }^{8}$ with similar mean age ( 41 years in CATIE vs $36-43$ years in other trials) and duration of illness ( 16.6 years in CATIE vs $14.7-16.3$ in other trials). The average baseline Positive and Negative Symptoms Scale total symptoms scores in CATIE was 76.1
$(S D=18.2$ ), notably lower than both the 87.5 $\langle S D=15.4)$ mean score in a major trial of olanzapine $^{9}$ and the $92.2(\mathrm{SD}=16.7)$ mean score in Marder's influential study of risperidone. ${ }^{10}$ Since these industry-sponsored studies did find advantages for olanzapine and ripseridone, greater chronicity of illness or severity of symptoms can not explain the difference in results.

Second, it is suggested that the CATIE findings are of no benefit of atypical antipsychotics compared to perphenazine are incomplete because they do not address how patients were feeling. The highly consistent no-difference findings, noted above, on multiple measures of symptoms, quality of life, and side effects, document in great detail that patients on atypicals were feeling no better than those on perphenazine. Marder may have been looking for more specific measures of how patients in CATIE felt about their medication. Data were collected regularly in CATIE using the Drug Attitude Inventory (DAI) ${ }^{11}$ a widely used 11-item measure of experiences on medication. A recent analysis of the DAI total scores in CATIE and of each of its 11 items using mixed models showed no significant difference between medications on the total DAl $(F=1.26, d f=3,604 ; P=.29)$ or any subscale (range of $P$ values $=.21-.75$ ), including between perphenazine and any atypical antipsychotic (data available on request).

Thirdly, it is suggested that there was insufficient time to measure tardive dyskinesia (TD) outcomes. A recent review ${ }^{12}$ of past studies could identify only four 1-year randomized trials of TD. These trials included 1,707 patients who were followed for an average of 8.8 months across the studies. These studies, taken together, were not substantially different in duration from CATIE, in which patients assigned to perphenazine and to the best performing second-generation antipsychotic (SGA), olanzapine, participated for a median of 5.6 and 9.2 months, respectively. ${ }^{2}$ While CATIE may not have been as long as opti- 
mally desirable for a study of TD, it was not much shorter than the studies that are cited as suggesting SGA benefits on this outcome, and thus its "no difference" findings may be no less informative.

While the review ${ }^{12}$ found a $4.6 \%$ lower annual risk of TD with SGAs $(0.8 \%$ vs $5.2 \%)$, the authors noted that the results could have been biased by the fact that all three head-to-head FGA-SGA comparison trials involved moderate-high doses of haloperidol 13-15 mg. Since CATIE found no advantage for SGAs using a similar TD measure, ${ }^{2}$ conclusions about TD benefits may not apply to intermediate potency first-generation antisychotics like perphenazine, used at reasonable doses.

While the growing use of SGAs has been credited by Marder with a general decline in TD among people with schizophrenia, recent reports raise doubts as to whether SGAs lead to substantial declines in either EPS or TD. ${ }^{13-16}$ TD may have declined in recent years because clinicians moved away from "mega-dose" strategies for FGAs that were in vogue during the late 1970s and 1980s.

Marder rightfully expresses concern about akathesia, which is stated as a factor in almost all treatment with high potency antipsychotics. CATIE showed clearly, however, that the risk of akathesia was no lower with any atypical than with perphenazine.

Some concern should be expressed about the suggestion in the title of the interview (for which he may not be responsible) that when the results of clinical trials are at odds with the clinical experiences of experts, the latter perhaps should take precedence. While clinical experience must guide care of individual patients and the development of public policy it cannot replace experimental research as the fundamental source of legitimacy of clinical medicine, and within it, of the profession of psychiatry. Many examples have emerged in recent years of costly and painful treatments that were deemed on the basis of clinical experience to be self-evidently effective-until double-blind studies showed them just as clearly not to be. ${ }^{16,17}$

The findings of CATIE were unexpected, but good science welcomes the unexpected, and learns and grows from it. To dismiss the findings of CATIE on the basis of clinical experience, would be to risk throwing out the baby of psychiatry's scientific legitimacy with the bathwater of the transient discomfort of finding long-held certainties challenged by new data.

Sincerely,

Robert Rosenheck, MD

\section{REFERENCES}

1. Marder SR. Newer antipsychotics and the difference between clinical experiences and clinical trials. CNS Spectr. 2007:12:812-815.

2. Lieberman JA, Stroup TS, McEvoy JP, et al, for the CATIE Investigators. Effectiveness of antipsychotic drugs in patients with chronic schizophrenia: primary efficacy and safety outcomes of the Clinical Antipsychotic Trials of Intervention Effectiveness (CATIE) schizophrenia trial. N Eng J Med. 2005;353:1209-1223.

3. Rosenheck RA, Leslie D, Sindelar J, et al. Cost-effectiveness of second generation antipsychotics and perphenazine in a randomized trial of treatment for chronic schizophrenia. Am J Psychiatry. 2006:163:2080-2089.

4. Keefe RSE, Bilder RM, Davis SM, et al; CATIE Investigators; Neurocognitive Working Group. Neurocognitive effect of antipsychotic medications in patients with chronic schizophrenia in the CATIE study. Arch Gen Psychiatry. 2007;64:633-647.

5. Swartz M, Perkins D, Stroup S, et al; CATIE Investigators. Effects of antipsychotic medications on psychosocial functioning in patients with chronic schizophrenia: Findings from the NIMH CATIE Study. Am J Psychiatry. 2007;164:428-436.

6. Resnick SG, Rosenheck RA, Stroup TS, et al for the CATIE Study Investigators. Employment outcomes in a randomized trial of second-generation antipsychotics and perphenazine in the treatment of individuals with schizophrenia. J Behav Health Serv Res. 2008; In press.

7. Swanson JW, Swartz MS, Van Dorn RA, et al for the CATIE Investigators. Effectiveness of antipsychotic drugs for reducing violence in persons with chronic schizophrenia: Findings from the NIMH CATIE Study. Br $J$ Psychiatry. 2008; In prešs.

8. Rosenheck RA, Stroup TS, Keefe RSE, McEvoy J, Swartz M. Lieberman JA. Study samples key to assessing risk [letter]. Current Psychiatry. 2007:6:3-4.

9. Tollefson GD, Beasley CM Jr, Tran PV, et al. Olanzapine versus haloperidol in the treatment of schizophrenia and schizoaffective and schizophreniform disorders: results of an international collaborative trial. Am J Psychiatry. 1997;154:457-465.

10. Marder SR, Meibach RC. Risperidone in the treatment of schizophrenia. Am J Psychiatry. 1994:151:825-835.

11. Hogan TP, Awad AG, Eastwood R. A self-report scale predictive of drug compliance in schizophrenics: reliability and discriminative validity. Psychol Med. 1983:13:177-183.

12. Correll CU, Leucht $S$, Kane JM. Lower risk for tardive dyskinesia associated with second-generation antipsychotics: a systematic review of 1-year studies. $A m J$ Psychiatry. 2004:161:414-425

13. Halliday J, Farrington S, Macdonald S, MacEwan T, Sharkey V, McCreadie R. Nithsdale Schizophrenia Surveys 23: movement disorders 20-year review. Br J PSychiatry. 2002;181:422-427.

14. Lee PE, Sykora K, Gill SS, et al. Antipsychotic medication and drug-induced movement disorder: a population-based cohort study in older adults. $J$ Am Geriatr Soc. 2005;53:1374-1379.

15. Rochon PA, Stukel TA, Sykora K, et al. Atypical antipsychotics and parkinsonism. Arch Intern Med. 2005:165:1882-1888.

16. Bausell RB. Snake Oil Science: The Truth About Complementary and Alternative Medicine. New York, NY: Oxford University Press; 2007.

17. Ariely $D$. The power of price: why a 50 -cent aspirin can do what a penny aspirin can't. In: Predictably Irrational: The Hidden Forces That Shape Our Decisions. New York, NY: HarperCollins; 2008;173-194.

Dr. Rosenheck is professor of psychiatry and epidemiology and public health at Yale School of Medicine in New Haven, Connecticut.

Disclosure: Dr. Rosenheck receives research/grant support from AstraZeneca, Bristol-Myers Squibb, and Eli Lilly; and receives consulting fees from Bristol-Myers Squibb, Eli Lilly, Janssen, and Organon.

\section{THE AUTHOR RESPONDS}

I am grateful for Dr. Rosenheck's careful reading of my interview. I agree that a clinician's clinical experiences should not be viewed as equivalent to the results of well designed clinical trials such as Clinical Antipsychotic Trials of Intervention Effectiveness (CATIE). On the other hand, when the results of clinical trials appear to differ from the experiences of clinicians it is important to understand the sources of these differences. 
I believe that some of these differences are actually shaped by some of the serious problems that come from relying on clinical experience. For example, clinical impressions of the first generation antipsychotics may have been shaped from the use of excessive doses of high potency drugs such as haloperidol or fluphenazine. Alternatively, clinicians may give excessive weight to the memories of the worst cases of extrapyramidal side effects and ignore the many patients who tolerated these older drugs. Pharmaceutical advertising may also influence the memories of clinicians. Each of these trends would tend to exaggerate any differences between first and second generation medications.

I do not think that discussing the possible limitations of the CATIE trial or any other study in any way undermines its value and its importance. Each study is limited to some degree by decisions made by the designers of the trial and other factors that cannot be totally controlled. For example, patients volunteered to be randomized in CATIE because they were probably dissatisfied with their medication response. The results may have been different if all patients meeting entry criteria were randomized if they wanted to change their antipsychotic or not. CATIE cannot provide this information.
I also raised the issue of whether there were factors that were important and not adequately measured. The unpublished findings from the Drug Attitude Inventory in the letter do suggest that subjective factors were measured.

Dr. Rosenheck expresses concern that the interview title ("Newer Antipsychotics and the Differences Between Clinical Experiences and Clinical Trials") suggests that I believe that experience should take precedence over data. This was not my intention and I do not understand how he reached this conclusion. On the other hand, I agree with him that good science welcomes the unexpected.

Sincerely,

Stephen R. Marder, MD

Dr. Marder is professor at the Semel Institute of Neuroscience and Human Behavior at the University of California, Los Angeles.

Disclosure: Dr. Marder is a consultant to Bristol-Myers Squibb, Merck, Otsuka, Pfizer, Roche, sanofi-aventis, and Solvay.

Please send letters to the editor to: CNS Spectrums, c/o Eric Hollander, MD, 333 Hudson St., 7th Floor, New York, NY 10013; E-mail: vi@mblcommunications.com.

\title{
Now Available Online at www.cnsspectrums.com
} ACADEMIC SUPPLEMENT

\author{
An expert panel review of clinical challenges in neurology
}

\section{Neuropsychiatric Aspects of Parkinson's Disease: Focus on Insomnia, Daytime Sleepiness, and Psychosis}

\author{
by Hubert H. Fernandez, MD, Shyamal Mehta, MD, PhD, John Morgan, MD, PhD, Kapil Sethi, MD, FRCP, \\ Joseph Friedman, MD, Richard Millman, MD, Gilles Fénelon, MD, PhD, and Laura Zahodne
}

To request a print supplement, pleasee-mail ks@mblcommunications.com Supported by Kyowa Pharmaceuticals, Inc. 